\title{
Analysis of a modular high efficiency Polygeneration System in a Science and Technological Park
}

\author{
Jordi Ortiga, Joan Carles Bruno and Alberto Coronas* \\ Universitat Rovira i Virgili, CREVER-Group of Applied Thermal Engineering, Tarragona, Spain, 43007
}

\begin{abstract}
Polygeneration systems refers to highly efficiency integrated systems characterized by the simultaneously production of different services (electricity, heating, cooling, water, etc) by means of several technologies using fossil and/or renewable energy sources. In many cases it is difficult to promote polygeneration projects due to its complexity. This complexity mainly comes from the high energy integration of the technologies involved in polygeneration plants and the high variability in the energy demand in many applications in the building sector that makes the design and optimal operation of these systems quite complex. The result is that without a very careful design and operation of these plants the economic viability is in many cases not clear.

In this paper is presented an economic, energetic and environmental analysis of a polygeneration system in Cerdanyola del Vallès (Spain) built in the framework of the Polycity project of the European Concerto Program. This polygeneration system comprises three high efficient natural gas cogeneration engines with a total power capacity of about 10 MW with advanced thermal cooling facilities including a single effect hot water driven chiller and a double effect chiller of 5 MW driven directly by the exhaust gases of the engines. This plant provides electricity, heating and cooling to a new Science and Technological Park in development including a Synchrotron Light Facility through a district heating and cooling network with a total length of more than $30 \mathrm{~km}$. The operational data for the energy performance analysis was taken using the plant SCADA system and a monitoring system specific for the cooling units in order to study in detail its performance. The results show that the polygeneration plant is an efficient way to reduce the primary energy consumption and $\mathrm{CO}_{2}$ emissions although it is not yet at its full capacity.
\end{abstract}

Keywords: polygeneration, trigeneration, modular design, high efficiency, district heating and cooling

\section{Introduction}

Polygeneration systems refers to highly efficiency integrated systems characterized by the simultaneously production of different services (electricity, heating, cooling, water, etc.) by means of several technologies using fossil and/or renewable energy sources to obtain a higher efficiency than that of an equivalent conventional system [1]. In many cases it is difficult to promote polygeneration projects due to its complexity. This complexity mainly comes from the high energy integration of the technologies involved in polygeneration plants and the high variability in the energy demand, especially in many applications in the building sector that makes the design and optimal operation of these systems quite complex.
Thus it is important a careful design, planning and optimal operational strategy of these systems in order to obtain economic benefits, to supply the energy demand to the users, and to obtain higher efficiencies than those of conventional alternatives [2]. This paper presents the design and operational results of a modular polygeneration plant [3] located in a technological park in Cerdanyola del Vallès (Spain) in the framework of the Polycity project of the European Concerto Program [4].

In the framework of the Polycity project a high efficiency energy polygeneration system was implemented in a new urban development called Parc de l'Alba. This area includes a Science and Technology Park with the Synchrotron Light Facility (ALBA) as well as residential buildings. The polygeneration system provides electricity, hot and chilled

${ }^{*}$ Corresponding author. Tel.: +34977 559665

Fax: +34977 559691; E-mail: alberto.coronas@urv.cat

(C) 2014 International Association for Sharing Knowledge and Sustainability

DOI: $10.5383 /$ ijtee.07.02.007 
water for the Synchrotron and the technological park buildings through a four-pipe district heating and cooling network. The polygeneration system comprises high efficiency natural gas engines driving thermal and compression cooling facilities and a district heating and cooling network connected to the final users. As these new area is under development, several phases have been planned including several polygeneration plants and the expansion of the district cooling and heating (DHC) networks. Figure 1 shows the foreseen polygeneration plants and DHC network:

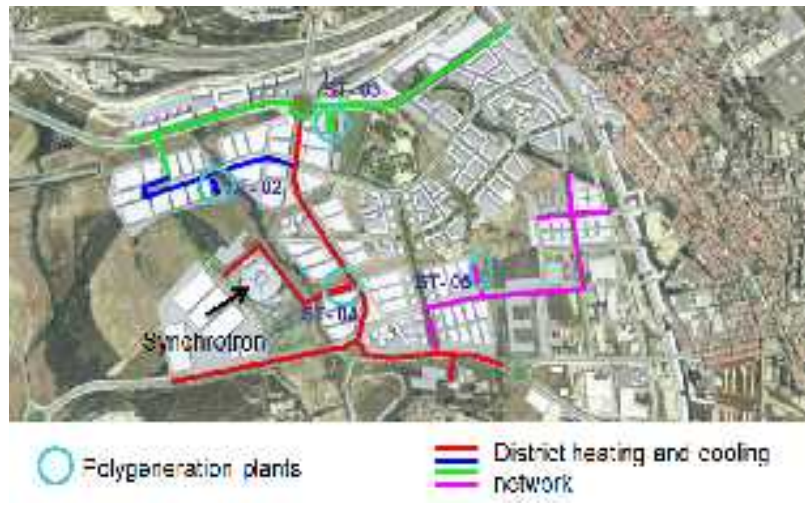

Figure 1 New Science and Technological Park

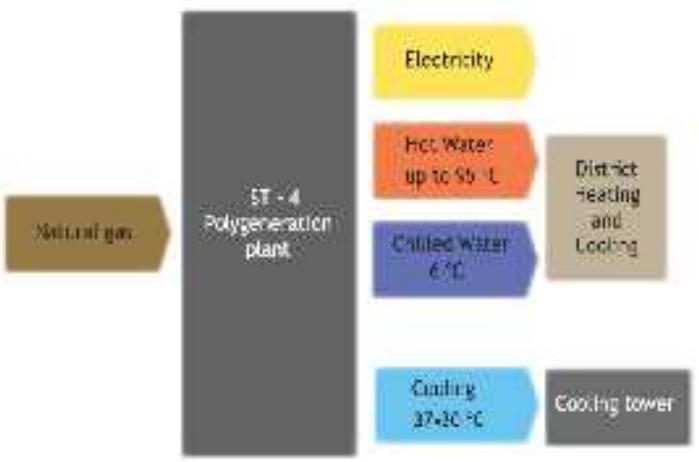

Figure 2 Energy services provided by the ST-4 energy plant

The first phase comprises the ST-4 plant and its DHC network providing hot and chilled water mainly to the synchrotron. The next phases include the extension of the ST-4 plant and the construction of new polygeneration plants and extension of the DHC as the energy demand of the park grows.

Initially due to the low occupancy of the park, the ST-4 plant was conceived using a modular design that allows extending the plant when energy demand grows up. ST-4 plant is composed of three gas cogeneration engines of 3.3 MW each one, a direct fired exhaust gas absorption chiller of $5 \mathrm{MW}$ using directly the engine exhausts gases, a single-effect absorption chiller of $3 \mathrm{MW}$ recovering heat from the engine jacket cooling, a compression chiller of $5 \mathrm{MW}$, a natural gas boiler of $5 \mathrm{MW}$ and a chilled water storage tank of $4000 \mathrm{~m}^{3}$. A simplified scheme of the ST-4 plant is presented in Figure 3

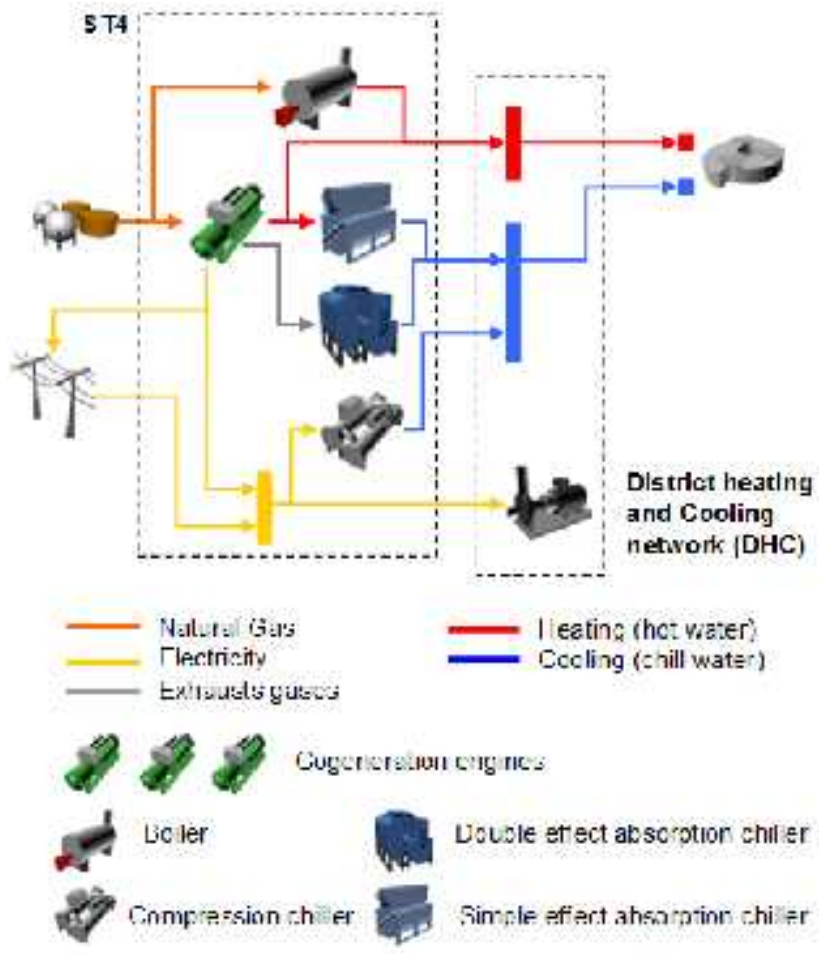

Figure 3 Schematic of the ST-4 energy plant

The three cogeneration engines produce electricity (maily sold to the grid) and wasted heat recovered from the hot water jacket circuit and the exhausts gases. Figure 4 shows the energy flow of each cogeneration engine at rated conditions.
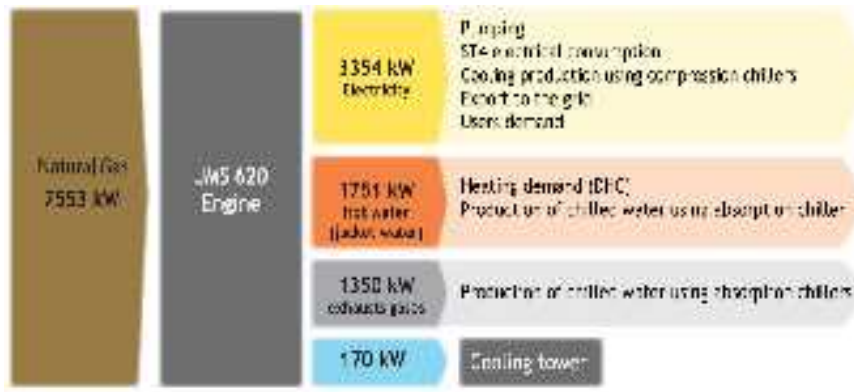

Figure 4 Energy flow of each cogeneration engine at rated conditions

The waste heat recovered from the jacket water circuit of the engines is used to produce hot water for the district heating network and to drive a simple effect (SE) absorption chiller of $3 \mathrm{MW}$. As a function of the chilled water demand and the operation conditions of the ST-4 plant, some of the exhausts gases pass through the double effect (DE) absorption chiller of $5 \mathrm{MW}$ to produce more chilled water. When the DE absorption chiller is not in operation, no heat is recovered from the exhausts gases. At rated conditions, the DE absorption chiller requires the exhausts gas flow rate of the three engines and the part load operation of the chiller is controlled by regulating the amount of exhausts gases passing through the chiller. 


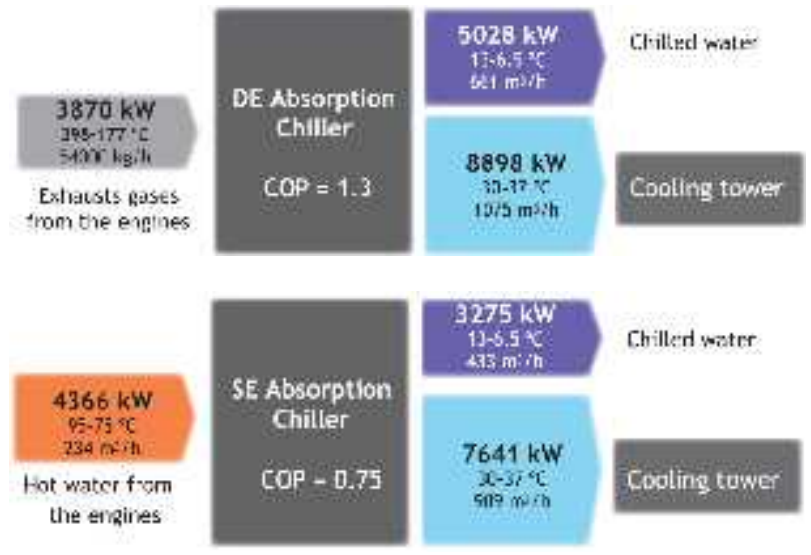

Figure 5 Energy flow of the DE and SE absorption chiller at rated conditions

A backup boiler and a compression chiller produce hot and chilled water respectively during very low demand periods (for example during the weekends). An underground chilled water storage tank enables the plant to shift demand peak loads. The tank can hold up to $4,000 \mathrm{~m}^{3}$ meaning $7 \mathrm{MW}$ for 2.5 hours with a temperature difference of $6^{\circ} \mathrm{C}$. A plate heat exchanger is used to charge or discharge the tank to the cooling network. Figure 6 and Figure 7 show an external and an internal picture of the ST-4 plant.

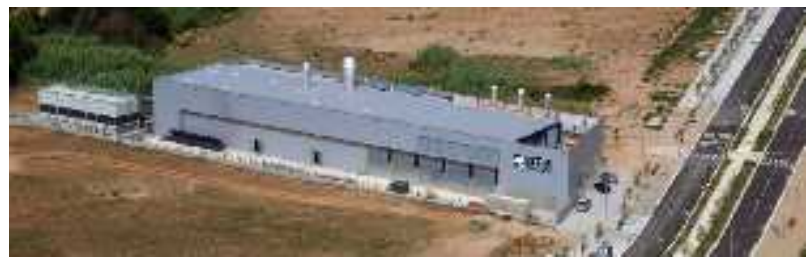

Figure 6 External view of the ST-4 energy plant

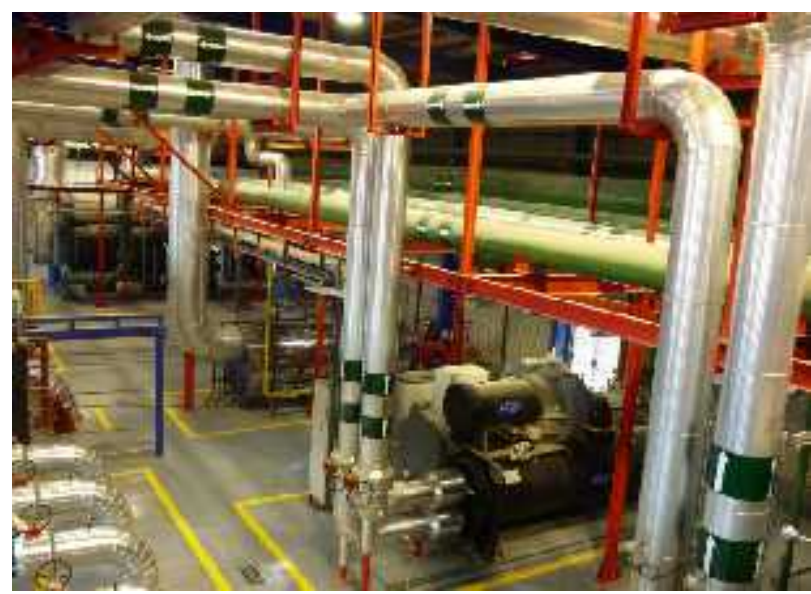

Figure 7 Internal view of the ST-4 energy plant

For economic reasons the three engines are working during the day, but the operation can be adapted as a function of the users demand (working with the required number of engines). In the same way, the recovery of heat from the engines, and the production of chilled water with the chillers are done as a function of the hot and chilled water demand. One, two or all chillers can work to fulfil the users demand. The underground chilled water storage tank adds flexibility to the operation of the plant, storing chilled water during the day and supplying chilled water during the night.
Due to the initial low energy demand, the ST-4 plant has been designed in a modular way allowing the addition of more units as the energy demand grows. The plant can hold up to 5 cogeneration engines of the same size that the existing ones, two DE absorption chiller driven by the exhausts gases of the engines, and two SE absorption chillers driven by the hot water produced with the engines. The enlargement of the plant will allow not only to increase of the energy production of the plant, with the connection of more users to the DHC, but also to increase the energy savings obtained with the operation of the plant. When considering the plant totally expanded, it is expected to achieve energy savings up to $25 \%$ under rated conditions $[5,6]$ with respect to state of the art conventional energy supply systems. Figure 8 shows the energy flow of the ST-4 plant considering all the expansions.
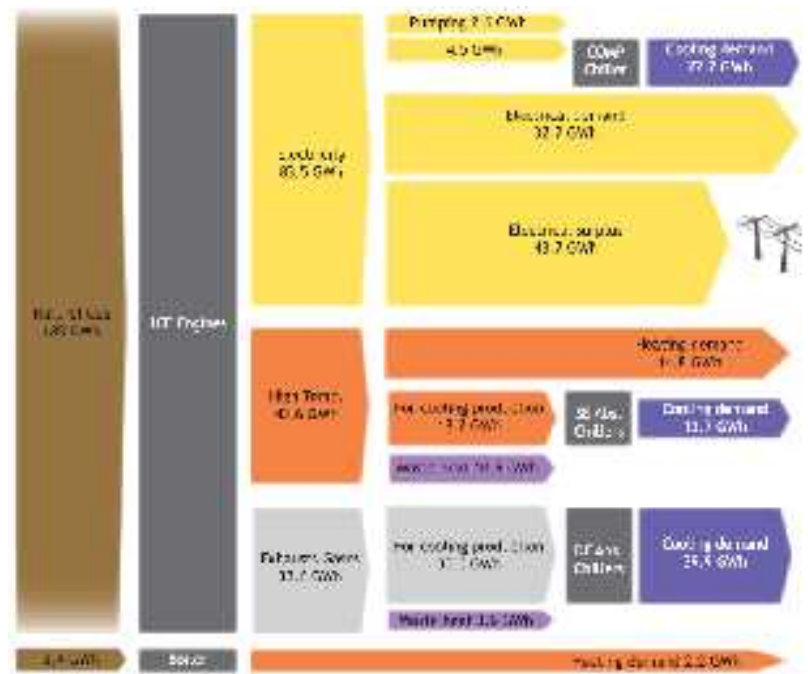

Figure 8 Energy flow for the ST-4 energy plant totally expanded

\section{Data acquisition system and energy demand}

An acquisition system has been installed in order to collect monitored values from the plant control system such us mass flow rates, temperatures, capacities, internal variables of the absorption chillers and other parameters. These values are recorded for each minute and are used to evaluate the performance of each unit and the whole plant. Figure 9 represents the control system and the data acquisition system installed in the ST-4 plant. The operation of the plant started in 2010 and since then the data acquisition system has been working, but due to technical reasons some data was missing. Figure 10 shows the months with monitored data and the ratio of time (for each month) that the data acquisition system has been working. 


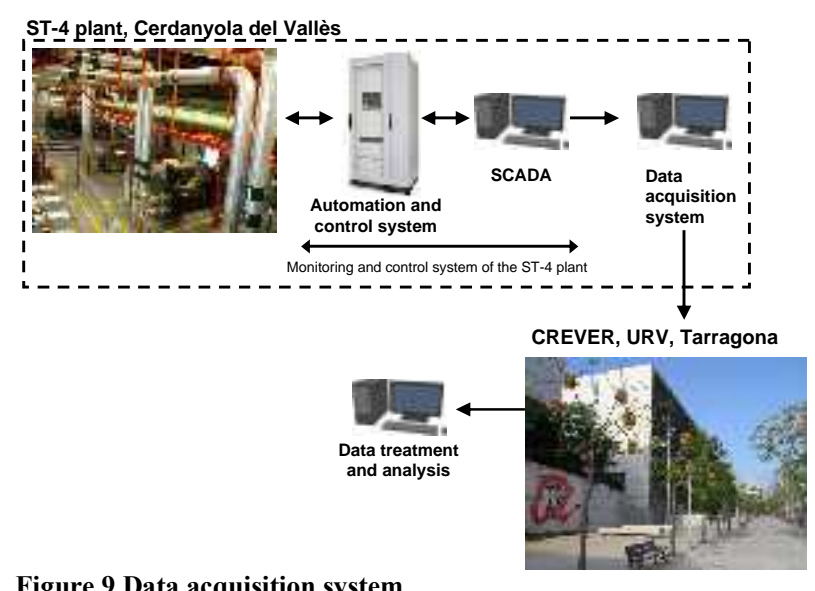

Figure 9 Data acquisition system

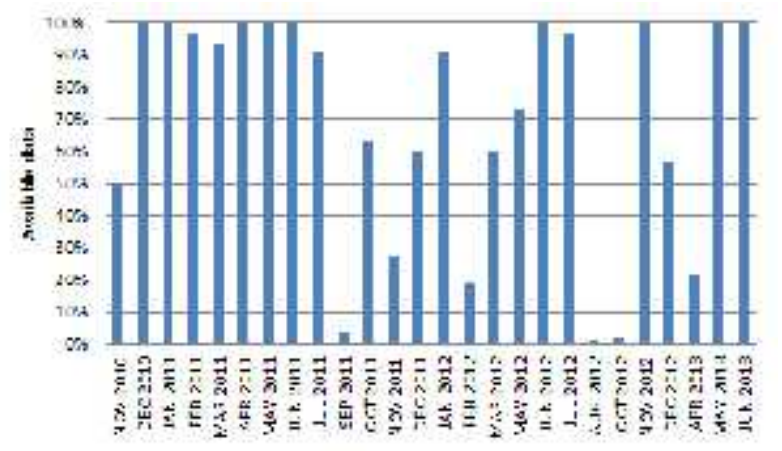

Figure 10 Available monthly data from the data acquisition system.

The first monitored results (2010-2011) showed an important difference between the expected energy demand (calculated in 2008 when the ST-4 plant was just designed) and the real one when the plant started. Figure 11 and Figure 12 shows the estimated and measured energy demand for chilled and hot water, respectively during the first months of operation. Due to the adverse economic situation the real energy demand is much lower than the initial expected energy demand. This behaviour has continued during the following years (2012 and 2013). Due to the low energy demand the ST-4 plant is working at very low part load with respect to the rated conditions decreasing the overall efficiency of the plant.

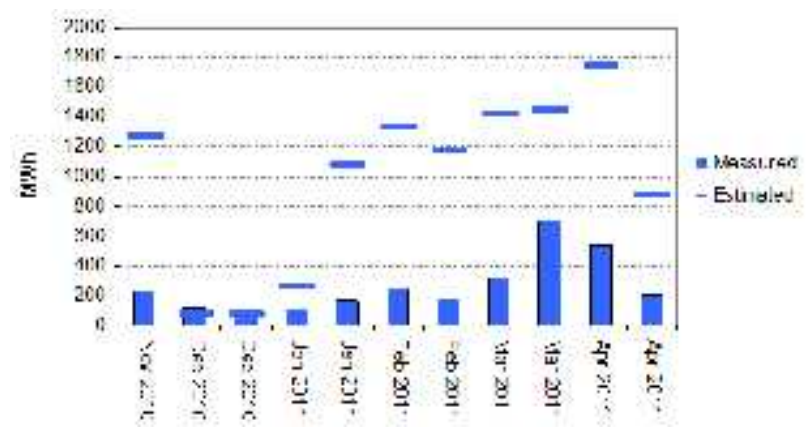

Figure 11 Initial chilled water demand (2010-2011)

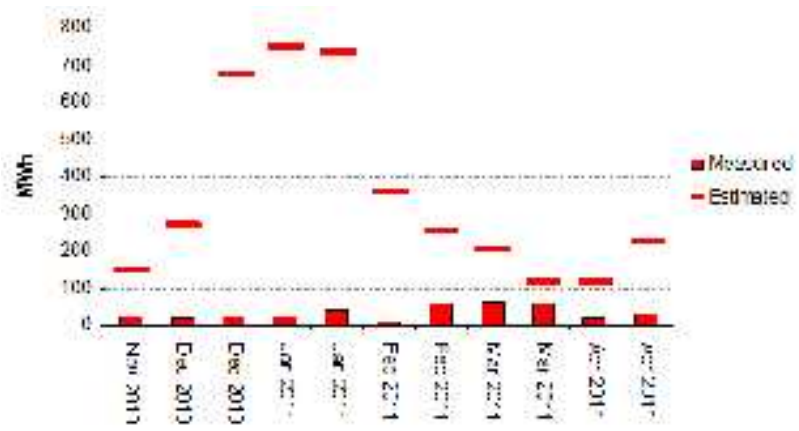

Figure 12 Initial hot water demand (2010-2011)

As it was seen in Figure 2 three products are obtained from the ST-4 plant: electricity, hot water and chilled water. As these three products are generated by integrated units working together, the capacity of the plant will be different as a function of which product has priority. Figure 13 shows the rated capacity of the plant as a function of different priorities, which are the following:

- Chilled water: priority is given to the production of chilled water.

- Hot-Chilled water: priority is given to the production of hot water, and later to the production of chilled water.

- Elec.-Chilled water: priority is given to the production of electricity, and later to the production of chilled water

- Elec.-Hot water: priority is given to the production of electricity, and later to the production of hot water

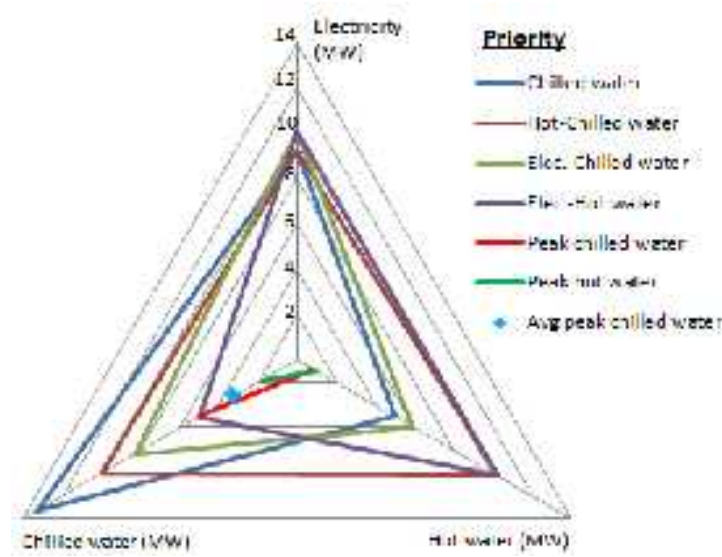

Figure 13 Maximum capacity of the plant (MW) considering different priorities

As a function of the priorities established, the net electrical capacity varies from 9.2 to $10.1 \mathrm{MW}$, the chilled water capacity from 5 to $13.3 \mathrm{MW}$ and hot water capacity from 5 to 10.3 MW. Considering the monitoring data obtained from November 2010 until June 2013, the peaks for chilled water demand and hot water demand has been plotted in Figure 13. "Peak chilled water" refers to the chilled and hot water demand when the peak of chilled water demand was reached (October 2011). "Peak hot water" refers to the chilled and hot water demand when the peak of hot water was reached (December 2011). In average the peaks of hot water demand are lower than $500 \mathrm{~kW}$. For the chilled water demand, the average peak during the last year of operation is around 3.3 MW ("Avg peak chilled water"). During the previous years this average peak is lower. 


\section{Electrical production}

Almost all the engines electrical production is sold to the grid. Under normal operation conditions the engines work with a constant time schedule for economic reasons. The monthly electricity production is quite constant (Figure 14). The periods with lower electric production are due to missing monitored data (see available data in Figure 10).

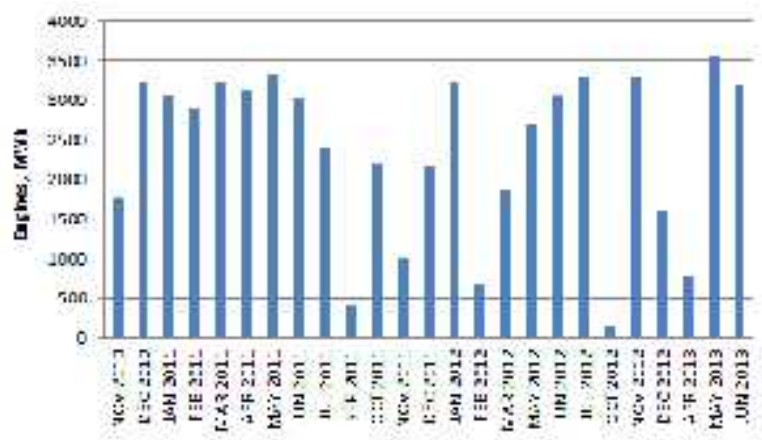

Figure 14 Total monthly electric production of the engines.

The three engines run almost at full load along the whole year (Figure 15). They only stop for technical/maintenance reasons. Figure 16 shows the monthly average electrical efficiency of the engines.

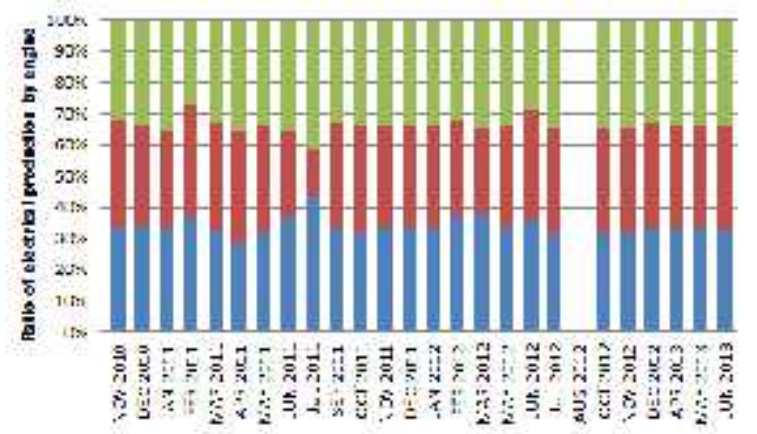

Figure 15 Sharing of the electric production between the engines.

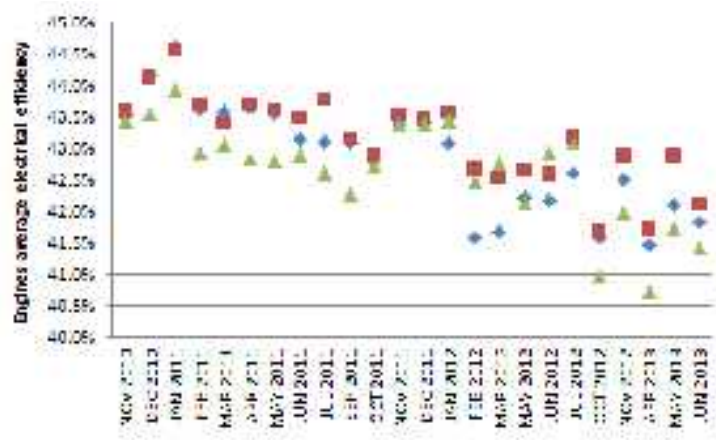

Figure 16 Monthly average engines electrical efficiency.

Figure 17 shows monthly useful hot water production from the jacket water of the engines and the boilers (due to the low energy demand not all the heat from the jacket water is recovered, the heat surplus is rejected with air coolers).

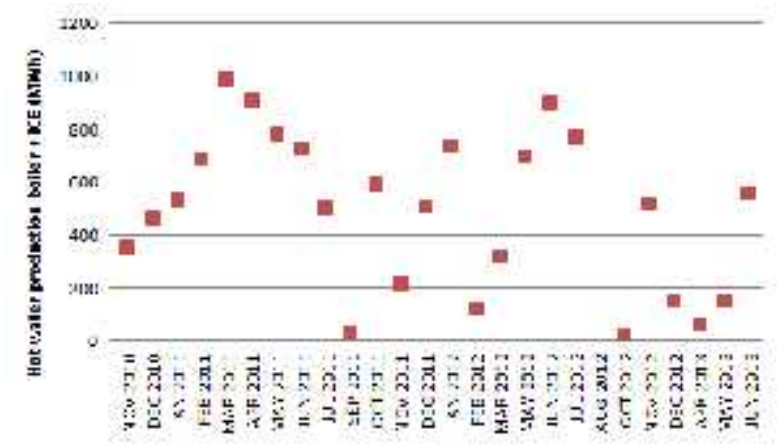

Figure 17 Useful production of hot water (engines+boiler)

\section{Chilled water production}

The demand of chilled water is higher than that for hot water demand and the ST-4 plant has been designed to produce chilled water using all the available wasted heat recovered, and the installation of the underground chilled water storage tank. Due to the user requirements, and the storage of chilled water and the loses in the district cooling network, the chilled water should be produce at quite low temperatures as shows Figure 18. The monthly average chilled water produced from the SE absorption chiller is below $5{ }^{\circ} \mathrm{C}$, and around $5.5^{\circ} \mathrm{C}$ for the $\mathrm{DE}$ absorption chiller.

In order to analyse the COP values obtained from the absorption chillers, cooling water temperature and the activation temperature are also important. Figure 19 shows the monthly average temperature for the inlet cooling water to each chiller, and Figure 20 shows the monthly average temperature Ergin 2 of the hot water generated by the engines. This hot water is mErginc : absorption chiller.

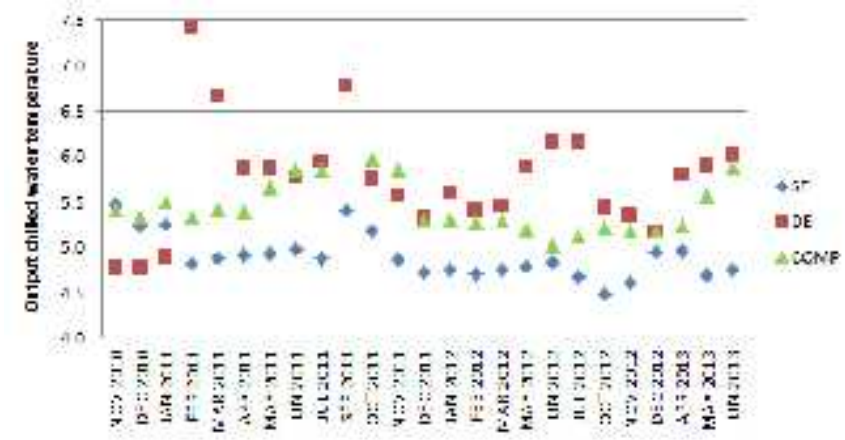

Figure 18 Monthly average temperature of the chilled water

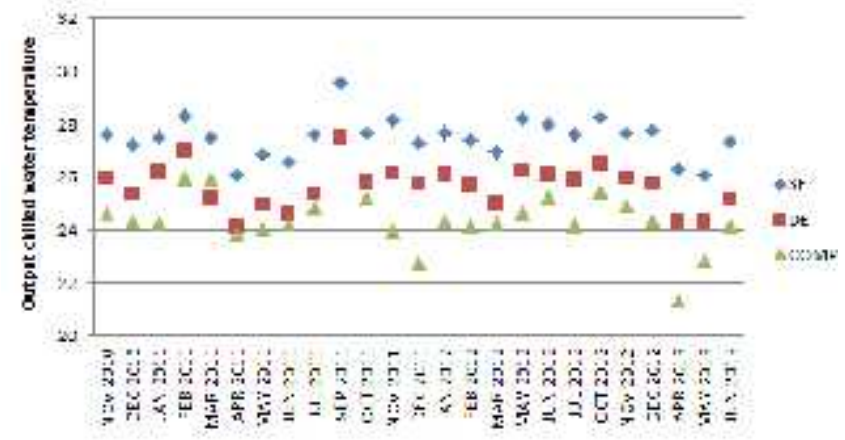

Figure 19 Monthly average temperature of the cooling water inlet temperature. 


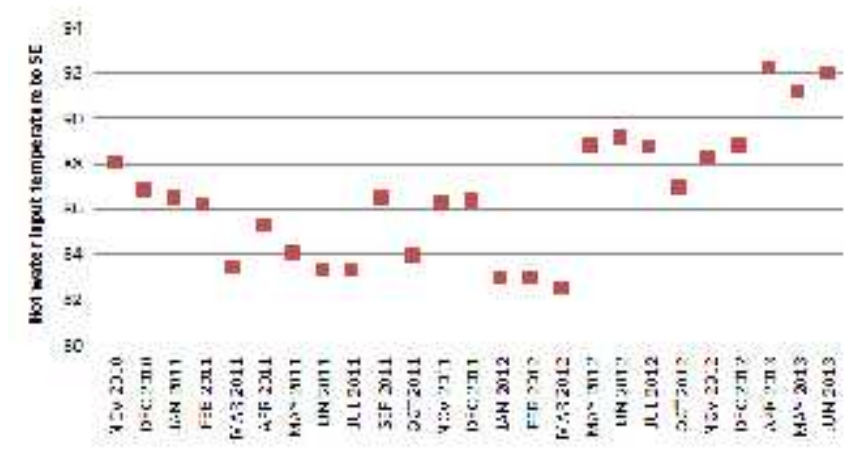

Figure 20 Monthly average monthly temperature of the hot water produced

The driven temperature of the DE absorption chiller is quite constant. At nominal conditions the output temperature of the exhausts gases of the cogeneration engines is around $380^{\circ} \mathrm{C}$. The part load operation of the DE absorption chiller is controlled by regulating the amount of exhausts gasses passing through the chiller. Figure 21 and Figure 22 show the monthly average $\mathrm{COP}$ for the SE and DE absorption chillers, respectively.

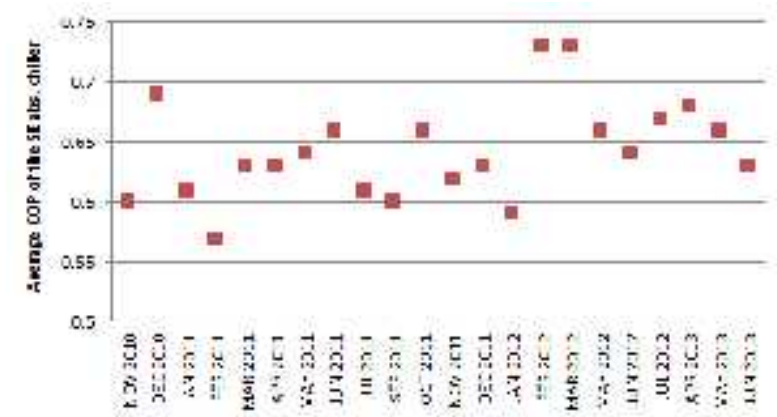

Figure 21 Monthly average COP for the SE absorption chiller

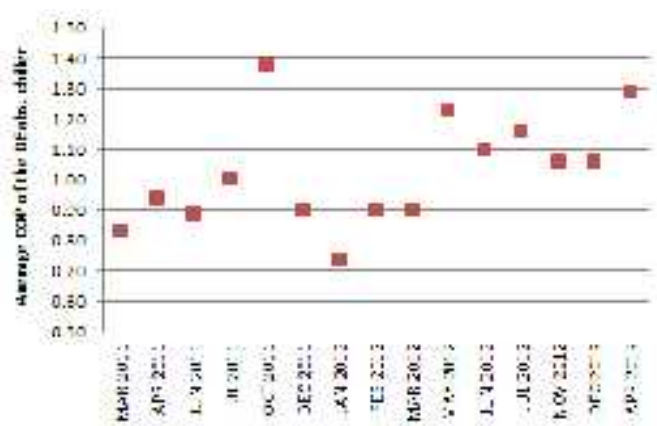

Figure 22 Monthly average COP for the DE absorption chiller

The COP obtained is lower with respect to rated conditions due to the different operating temperature conditions of the chillers and the fact that almost all the time they are working at partial load due to a low chilled water demand. Figure 23 shows the total chilled water production of the plant. Months with lower production are due to missing monitoring data (see Figure 10). From this figure it can be seen a higher energy demand in 2012 (for example June - July 2012) with respect to 2011 (May June 2011). Despite this slight increment, the demand is still very far from the capacity of the plant. Figure 24 shows chilled water production distribution among the three chillers. Compression chillers are used to supply the chilled water demand during the weekends (when all the other units are not in operation) or as backup when one of the absorption chillers are not in operation (December 2010, July 2012, June 2013).

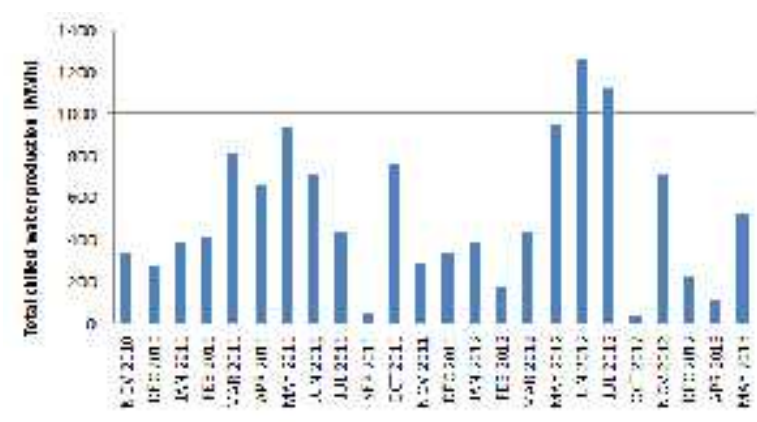

Figure 23 Total chilled water production

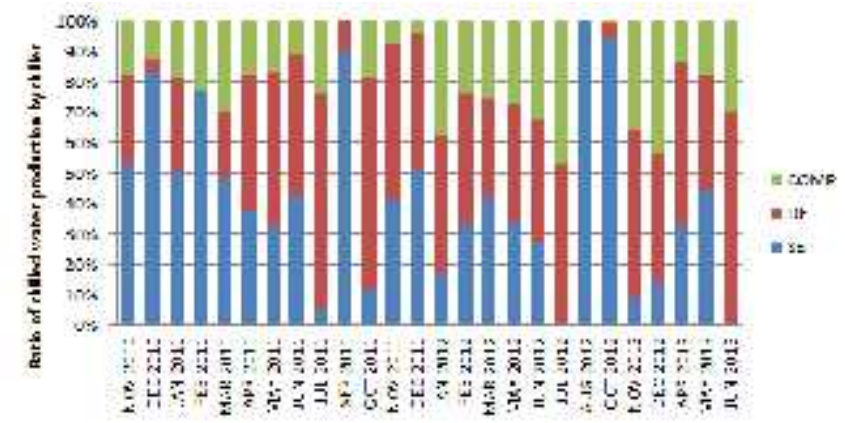

Figure 24 Total chilled water production.

\section{Conclusions}

In this paper it is presented a modular polygeneration plant composed of high efficiently cogeneration engines and two types of absorption chillers among others units. The features of this plant is the use of cogeneration engines with a high electrical efficiency up to $44 \%$ and the use of exhausts gases directly to drive a double effect absorption chiller. The hot water from the engines can be used to cover the heating demand and to produce cooling by means of a simple effect absorption chiller. An underground chilled water storage tank allows coupling the chilled water production with the demand. Considering rated conditions the plant will be able to save up to $25 \%$ of primary energy with respect to a conventional energy supply system. As the temperature of the hot water recovered from the engines increases the heat losses increase in the DH network but the COP in the SE absorption chiller increases. Due to several problems the energy demand is very low with respect to the installed capacity. This low energy demand affects the heat recovery from the engines and the chillers work at partial load. Energy savings will increase as energy demand increases in the future.

The ST-4 energy plant can be expanded if more users get connected in the future and the energy demand grows. The plant can hold up to 5 cogeneration engines, 2 double effect absorption chillers and 2 simple effect absorption chillers. Overall efficiency of the plant would increase if energy consumption is increased. Due to the low energy demand, the operation schedule of the plant (working hours of the engines) are fixed in order to assure economic benefits. Chillers are not working during the night because of the low energy demand. If the energy demand could increase, the operational schedule of the plant would be different allowing the absorption chillers to work longer. Due to the transient behavior, the efficiency of the plant would increase if absorption chillers operate continuously during day and night from Monday to Friday. 


\section{Acknowledgment}

The authors gratefully acknowledge the support of the PolyCity project (Energy networks in sustainable communities) of the CONCERTO initiative co-funded by the European Commission within the Sixth Framework Programme (FP6) Project n: TREN/05FP6EN/S07.43964/ 51381 and to all the staff of the ST4 energy plant.

\section{References}

[1] D. Österreicher, O. Pol, "Concerto initiative and polygeneration", presented at the 1st European Conference on Polygeneration, Tarragona, Spain, 2007.

[2] G. Chicco, P. Mancarella, "Distributed multi-generation: A comprehensive view", Renewable \& Sustainable Energy Reviews, 2009, vol. 13, pp. 6132-6144
[3] Parc del Alba - Polygeneration plant ST4:

http://www.parcdelalba.com/en/current_stauts/urban_services/po lygeneration_plant

[4] PolyCity: http://www.polycity.net

[5] J. Ortiga, J.C. Bruno, A. Coronas, "A modular formulation of mathematical programming models for the optimization of energy supply systems", presented at the 19th European Symposium on Computer Aided Process Engineering, Krakow, Poland, 2009.

[6] J. Ortiga, "Modelling Environment for the Design and Optimisation of Energy Polygeneration Systems" Ph.D. dissertation, Dept. Mecanical. Eng., Univ. Rovira I Virgili, Spain, 2010

[7] J. Ortiga, J.C. Bruno, A. Coronas, "Operational Optimisation of a Complex Trigeneration System Connected to a District Heating and Cooling Network", presented at the 2nd European Conference on Polygeneration, Tarragona, Spain, 2011. 